\title{
CRESCIMENTO E PRODUÇÃO DO ARROZ SOB DIFERENTES PROPORÇÕES DE NITRATO E DE AMÔNIO(1)
}

\author{
Josinaldo Lopes Araújo(2), Valdemar Faquin( ${ }^{(3)}$, Neiva Maria Batista \\ Vieira $^{(4)}$, Marcos Vanner Carvalho de Oliveira( ${ }^{(5)}$, Antônio Alves \\ Soares $^{(6)}$, Carlos Ribeiro Rodrigues ${ }^{(7)}$ \& Alessandro Carlos Mesquita ${ }^{(8)}$
}

\begin{abstract}
RESUMO
As plantas diferem quanto à preferência pela forma de $\mathrm{N}$ mineral a ser absorvida e metabolizada. No arroz, essa preferência parece variar com o estádio de crescimento da cultura. O presente trabalho objetivou avaliar o efeito de proporções de $\mathrm{N}$-nitrato e de $\mathrm{N}$-amônio sobre o crescimento e a produção de grãos das cultivares de arroz de terras altas BRS Colosso e BRSMG Conai em solução nutritiva, em dois experimentos, um com cada cultivar. Em ambos os experimentos o delineamento utilizado foi o inteiramente casualizado, com quatro repetições, em esquema de parcelas subdivididas no tempo. As parcelas primárias foram constituídas por cinco relações $\mathrm{N}$-nitrato $\left(\mathrm{N}-\mathrm{NO}_{3}{ }^{-}\right)$: $\mathrm{N}$-amônio $\left(\mathrm{N}-\mathrm{NH}_{4}{ }^{+}\right)(100: 00,80: 20,60: 40,50: 50$ e 40:60), e as subparcelas, por estádios de crescimento do arroz (início do perfilhamento, diferenciação do primórdio floral e início da emissão de panículas). $\mathrm{O}$ fornecimento de $\mathrm{N}$ na forma exclusiva de nitrato, ou de amônio em maiores proporções que o nitrato, diminuiu a produção de matéria seca das cultivares de arroz, principalmente na época da emissão de panículas, alterando também a produção de grãos. A máxima produção de matéria seca da parte aérea das cultivares de arroz ocorreu para proporções de nitrato entre 58 e $68 \%$. Para a produção de grãos, os máximos foram obtidos com proporções de nitrato entre 75 e $78 \%$. A causa do menor crescimento e da produção das cultivares de arroz quando se forneceu apenas nitrato foi o acúmulo
\end{abstract}

(1) Parte da Dissertação de Mestrado do primeiro autor apresentada ao Programa de Pós-Graduação em Ciência do Solo, da Universidade Federal de Lavras - UFLA. Recebido para publicação em 18 de outubro de 2010 e aprovado em 2 de março de 2012.

(2) Professor do Centro de Ciências e Tecnologia Agroalimentar, Universidade Federal de Campina Grande - UFCG. Rua Cel. João Leite, 517, Centro, 58840-000 Pombal (PB). E-mail: josinaldo@ccta.ufcg.edu.br.

(3) Professor Titular do Departamento de Ciência do Solo, Universidade Federal de Lavras - UFLA. Caixa Postal 3037, CEP 37200000 Lavras (MG). E-mail: vafaquin@ufla.br

(4) Professora do Instituto Federal de Educação, Ciência e Tecnologia do Sul de Minas Gerais, Campus Machado, Rod. MachadoParaguaçu, km 3, s/n CEP 37750-000 Machado (MG). E-mail: neivavieira2003@yahoo.com

(5) Doutor em Fitotecnia pelo Departamento de Agricultura, UFLA. E-mail: mvanner@bol.com.br

(6) Professor Associado II do Departamento de Agricultura, UFLA. E-mail: aasoares.dag.ufla.br

(7) Professor da Universidade Federal de Pernambuco - UFPE. Unidade Acadêmica de Garanhuns, Av. Bom Pastor s/n, Boa Vista, CEP 55296-901 Garanhuns (PE). E-mail: carlos_rrodrigues@yahoo.com.br

(8) Doutor em Fisiologia Vegetal pelo Departamento de Biologia, UFLA. E-mail: mesquita@ufla.br 
excessivo dessa forma nos tecidos das plantas na fase inicial do seu crescimento, devido à baixa atividade da redutase do nitrato nessa fase. Entretanto, houve efeito prejudicial também pelo excesso de amônio, quando este se encontrava em maiores proporções que o nitrato na solução nutritiva.

Termos de indexação: redutase do nitrato, acúmulo de nitrato, arroz de terras altas.

\title{
SUMMARY: RICE GROWTH AND YIELD AT DIFFERENT NITRATE- AMMONIUM RATIOS
}

\begin{abstract}
Plants differ in preference for mineral nitrogen forms for uptake and metabolism. In rice plants, this preference can be associated with the growth stage. This study aimed to evaluate the growth, $N$ nutrition and yield of the rice cultivars BRS Colosso and BRSMG Conai in nutrient solution with different ratios of nitrate and ammonium. The experiment was arranged in a completely randomized design in split plots with four replications. The plots were represented by five $\mathrm{N}$-nitrate $\left.\left(\mathrm{N}-\mathrm{NO}_{3}\right)^{-}\right)$: $\mathrm{N}$-ammonium $\left(\mathrm{N}-\mathrm{NH}_{4}{ }^{+}\right)$ratios (100:00, 80:20, 60:40,50:50, and 40:60) and the subplots by the three growth stages. $N$ supply in the exclusive form of nitrate, or ammonium at higher proportions than nitrate, decreased dry matter, especially during panicle emission, affecting the yield. The maximum dry matter production of rice cultivars shoots occurred at nitrate rates between 58 and $68 \%$. The maximum grain yield was obtained at nitrate ratios between 75 and $78 \%$. The excessive accumulation of nitrate in plant tissues due to low activity of nitrate reductase in the initial growth phase, and excess of ammonium were the main causes of decline in rice growth and yield, when nitrate was the only $N$ form or when ammonium was used at higher proportions than nitrate in the nutrient solution.
\end{abstract}

Index terms: nitrate reductase, nitrate accumulation, upland rice.

\section{INTRODUÇÃO}

O suprimento adequado e a capacidade de absorção e assimilação de $\mathrm{N}(\mathrm{N})$ pelo arroz são determinantes para a obtenção de rendimentos satisfatórios pela cultura (Fageria et al., 2003). O N é exigido durante todo o período vegetativo do arroz, porém duas fases fisiológicas merecem atenção especial: o início do perfilhamento e o início da diferenciação do primórdio floral (Wada et al., 1986). O suprimento adequado de $\mathrm{N}$ durante o início do perfilhamento resulta em produção de maior número de perfilhos férteis e, consequentemente, em maior produção (Matsuo \& Hoshikawa, 1993; Farinelli et al., 2004).

No solo, o $\mathrm{N}^{-\mathrm{NO}_{3}}{ }^{-}$(N na forma nítrica) e o $\mathrm{N}-\mathrm{NH}_{4}{ }^{+}$ ( $\mathrm{N}$ na forma amoniacal) são as principais formas de $\mathrm{N}$ disponíveis às plantas, sendo a primeira forma predominante em solos aerados. Ambas as formas podem ser utilizadas pelas plantas em proporções que dependem da espécie ou do genótipo, bem como da disponibilidade de carboidratos para o metabolismo vegetal (Nambiar, et al., 1988; Qian et al., 2004; Epstein \& Bloon, 2006).
$\mathrm{O}$ fornecimento de $\mathrm{N}$ exclusivamente como $\mathrm{N}-\mathrm{NO}_{3}$ - pode resultar em diminuição da produção de matéria seca e de grãos em plantas que apresentam baixa capacidade de reduzir nitrato, pois, para que o $\mathrm{N}$ desempenhe suas funções na planta, é necessário que ele seja reduzido e incorporado a compostos orgânicos (Ali et al., 2007). Altos níveis de amônio nos tecidos celulares, por outro lado, podem ser tóxicos e provocar efeitos negativos sobre o crescimento radicular e da parte aérea (Cramer \& Lewis, 1993; Oaks, 1994), causando distúrbios fisiológicos (Mengel \& Kirby, 1987) e nutricionais (Holzschuh et al., 2009).

A forma de $\mathrm{N}$ preferencial a ser absorvida e assimilada varia com a espécie de planta (Qian et al., 2004; Noma \& Hirose, 2005; Duan et al., 2006, 2007). No arroz, a utilização preferencial de uma das formas de $\mathrm{N}$ em detrimento da outra tem gerado uma série de trabalhos, cujos resultados ainda não são conclusivos. A utilização do $\mathrm{N}-\mathrm{NO}_{3}$ em maiores proporções em relação ao $\mathrm{N}-\mathrm{NH}_{4}{ }^{+}$pode estar relacionada com a idade da planta (Malavolta, 1980; Ouko, 2003; Soares, 2004). Esse fato levou 
Soares (2004) a sugerir que uma das causas do insucesso do cultivo do arroz em sistema de plantio direto é o fato de as plantas de arroz na fase inicial do crescimento apresentarem baixa capacidade de redução do $\mathrm{N}_{-} \mathrm{NO}_{3}$, que, devido às condições favoráveis ao processo de nitrificação, seria a forma de $\mathrm{N}$ mineral predominante na camada superficial de solos sob esses sistemas. O não aproveitamento do $\mathrm{N}^{-} \mathrm{NO}_{3}$ - na fase inicial do crescimento seria em razão da baixa atividade da enzima redutase do nitrato, a qual converte nitrato em nitrito, para então a redutase do nitrito converter o nitrito em amônio, a fim de este último ser incorporado em compostos orgânicos (Ali et al., 2007). Esse aspecto é particularmente importante quando se considera que o cultivo do arroz de sequeiro corresponde a $66 \%$ da área total cultivada com arroz no Brasil e contribui com apenas $31 \%$ da produção nacional, sendo esse resultado supostamente explicado pela baixa produtividade desse sistema (Soares, 2004). Dessa forma, a hipótese do presente trabalho é de que no início do seu perfilhamento o arroz apresenta baixo aproveitamento de $\mathrm{N}$-nitrato, o que compromete seu crescimento e desenvolvimento, refletindo em menor produção de grãos.

Este trabalho objetivou avaliar o efeito de proporções de $\mathrm{N}$-nitrato e de $\mathrm{N}$-amônio em solução nutritiva sobre o crescimento e a produção de grãos de duas cultivares de arroz de terras altas.

\section{MATERIAL E MÉTODOS}

Dois experimentos foram conduzidos em casa de vegetação do Departamento de Ciência do Solo da Universidade Federal de Lavras (UFLA), LavrasMG: um com a cultivar de arroz (Oryza sativa L.) BRS Colosso e outro com a cultivar BRSMG Conai (de ciclo mais curto que a Colosso), ambas recomendadas para sistemas de cultivo de terras altas. As sementes das cultivares foram germinadas em papel germitest em câmara de germinação. Após a germinação, as plântulas de cada cultivar foram transferidas para bandejas de polietileno contendo 8 L de solução de Hoagland e Arnon (Hoagland \& Arnon, 1950), com $20 \%$ de sua força iônica e os respectivos tratamentos (Quadro 1), recebendo arejamento constante. Após 14 dias de cultivo, a força iônica da solução foi aumentada para $50 \%$ e mantida até o final dos experimentos. O volume de solução das bandejas foi completado diariamente com água deionizada, e a troca da solução foi realizada a cada sete dias, sendo o $\mathrm{pH}$ mantido entre 5,5 e 6,0 pela adição de $\mathrm{NaOH}$ ou $\mathrm{HCl} 1,0 \mathrm{~mol} \mathrm{~L}^{-1}$.

Os experimentos foram instalados em esquema de parcelas subdivididas no tempo, em delineamento inteiramente casualizado. As parcelas primárias foram constituídas por cinco relações $\mathrm{N}$-nitrato $\left(\mathrm{N}-\mathrm{NO}_{3}{ }^{-}\right)$: N-amônio $\left(\mathrm{N}^{-} \mathrm{NH}_{4}{ }^{+}\right)(100: 00,80: 20,60: 40$, 50:50 e 40:60) em solução nutritiva, e as subparcelas, por três estádios de crescimento do arroz: 26 (início do perfilhamento), 41 (diferenciação do primórdio floral) e 70 (início da emissão de panículas) dias após o transplantio (DAT). Para as variáveis número de panículas e produção de grãos obtidas na época da colheita, os tratamentos foram constituídos pelas cinco relações N-nitrato:N-amônio. Em cada experimento, empregaram-se quatro repetições, as quais foram compostas por uma bandeja contendo 24 plantas.

Nas avaliações realizadas aos 26, 41 e 70 DAT, duas plantas de cada repetição dos tratamentos foram destinadas ao ensaio da atividade da redutase do nitrato, conforme Delú Filho et al. (1997). Outras duas plantas de cada repetição, em cada estádio de crescimento, foram separadas em caule + folhas e

\section{Quadro 1. Soluções-estoque e volumes pipetados para o preparo das soluções dos tratamentos}

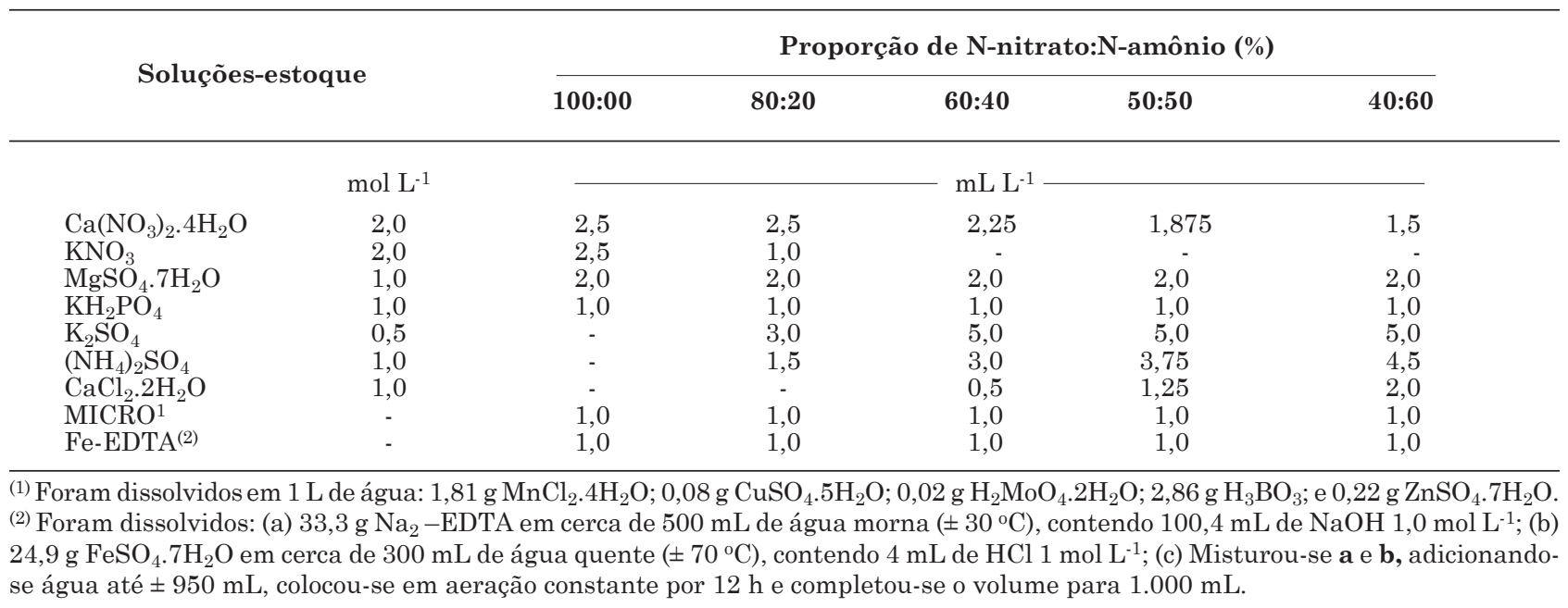


raízes, secas em estufa de circulação forçada de ar a $65-70{ }^{\circ} \mathrm{C}$ até peso constante, pesadas, obtendose a matéria seca da parte aérea (MSPA) e de raízes (MSR). Em seguida, o material vegetal seco foi moído e destinado à determinação do N-total, segundo Malavolta et al. (1997), e N-mineral (N$\mathrm{NH}_{4}{ }^{+}$e N-NO${ }_{3}{ }^{-}$), conforme Tedesco et al. (1985). O $\mathrm{N}$-orgânico foi obtido pela diferença entre o $\mathrm{N}$-total e o $\mathrm{N}$-mineral. De posse dos teores das formas de $\mathrm{Ne}$ da matéria seca produzida pelas respectivas partes das plantas, foram obtidos os totais acumulados por planta de $\mathrm{N}-\mathrm{NH}_{4}{ }^{+}, \mathrm{N}^{-\mathrm{NO}_{3}}{ }^{-}$, N-total e N-orgânico.

As plantas restantes de cada repetição foram destinadas à avaliação da produção de grãos, sendo conduzidas até a maturação destes (120 DAT para a cultivar BRSMG Conai e 140 DAT para a BRS Colosso). Ao fim desse período, foi realizada a colheita, separando-se as panículas para a determinação do número de panículas por planta e produção de grãos com casca por planta a $13 \%$ umidade.

As variáveis foram avaliadas mediante análise de variância e análise de regressão polinomial, quando pertinente, a $5 \%$. As análises de regressão polinomial foram feitas considerando como variável independente as proporções de N-nitrato em solução nutritiva.

\section{RESULTADOS E DISCUSSÃO}

\section{Crescimento e produção}

As proporções de nitrato e os estádios de crescimento influenciaram $(\mathrm{p}<0,05)$ a produção de matéria seca da parte aérea (MSPA) e de raízes (MSR) em ambas as cultivares (Figura 1). No início (a)

BRS Colosso

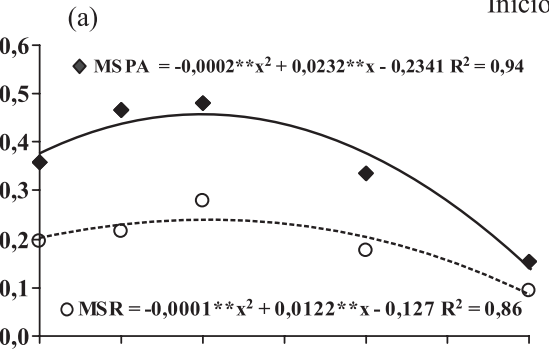

BRSMG Conai

Início do perfilhamento (26 DAT)

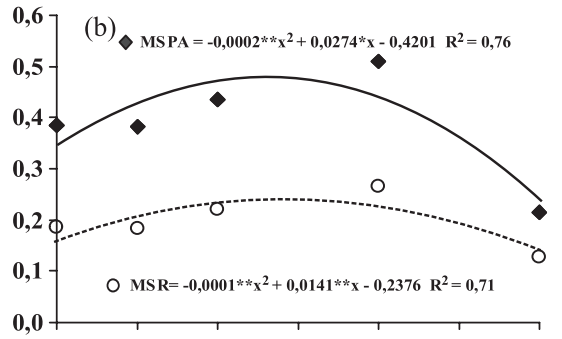

Diferenciação do primórdio floral (41 DAT)
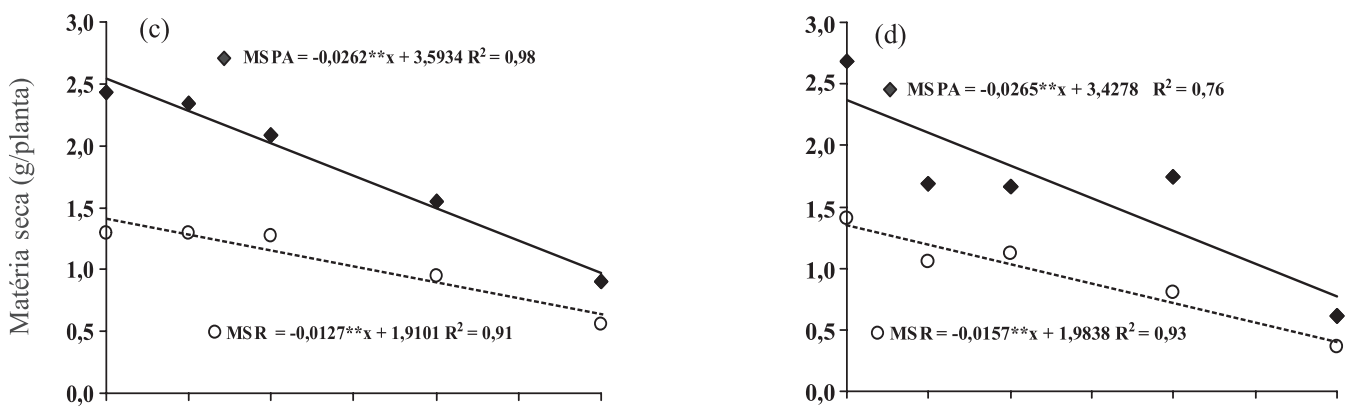

Início da emissão de panículas (70 DAT)
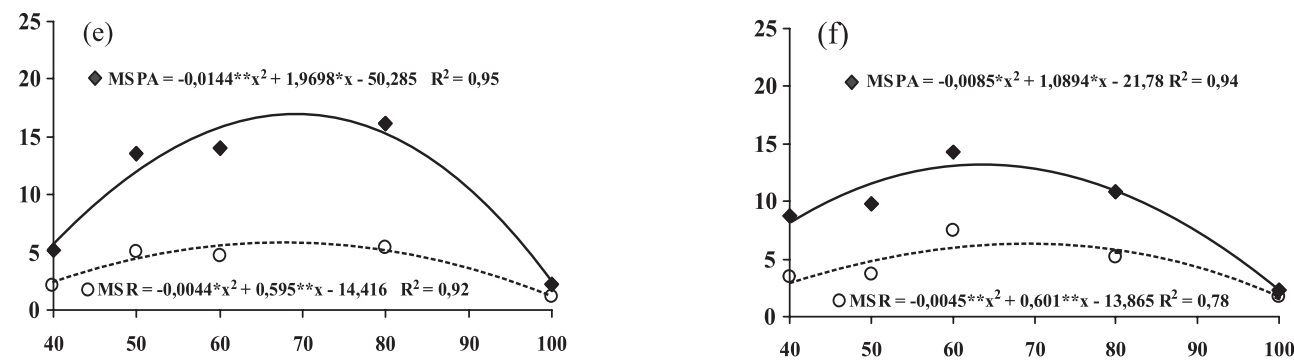

Proporções de nitrato (\%)

Figura 1. Matéria seca da parte aérea (MSPA) e matéria seca de raízes (MSR) das cultivares de arroz BRS Colosso (a, c e e) e BRSMG Conai (b, d e f) em função das proporções de nitrato na solução nutritiva, em diferentes estádios de crescimento. DAT: dias após o transplantio. * $\mathrm{e}^{* *}$ : Significativo em níveis de $p<0,05$ e $p<0,01$, respectivamente. 
do perfilhamento (26 DAT) e na época da emissão de panículas (70 DAT), a produção de matéria seca (MSPA e MSR) seguiu o modelo quadrático em função das proporções de nitrato em solução nutritiva (Figura 1a,b,e,f), enquanto no estádio de diferenciação do primórdio floral (41 DAT) o ajuste foi linear (Figura 1c,d).

Observou-se que o fornecimento de $\mathrm{N}$ exclusivamente como nitrato reduziu acentuadamente a MSR e a MSPA em ambas as cultivares, em todos os estádios de crescimento. A redução na matéria seca das plantas pelo fornecimento exclusivo de $\mathrm{N}$-nitrato, ou de $\mathrm{N}$-amônio em maiores proporções, tem sido constatada em outros trabalhos, tanto em gramíneas quanto em dicotiledôneas (Ganmore-Neumann \& Kafkafi, 1980; Holzschuh et al., 2009). A esse respeito, é relatado em Malavolta (1980) que o arroz, tanto de sequeiro quanto o irrigado, nas duas ou três primeiras semanas após a emergência, quando cultivado em meio contendo $\mathrm{N}$-nitrato como forma exclusiva de $\mathrm{N}$, desenvolve-se muito pouco, apresentando sintomas típicos de deficiência de $\mathrm{N}$, o que não acontece quando o $\mathrm{N}$ é fornecido como $\mathrm{N}$ -amônio. Esses fatos foram observados e relatados também por Araújo (2005). Assim, o baixo aproveitamento de $\mathrm{N}$-nitrato na fase inicial do crescimento poderia ser a principal causa da redução do crescimento e da produção de grãos de arroz.

Para a cultivar BRS Colosso, as maiores produções de MSPA, no início do perfilhamento e início da emissão de panículas, ocorreram quando a proporção de nitrato na solução nutritiva foi de 58 e $68 \%$, respectivamente. Quanto a BRSMG Conai, essas proporções foram de 68 e $67 \%$, respectivamente.
Aos 41 DAT, época da diferenciação do primórdio floral, também foi verificada redução na produção de matéria seca pelo efeito do nitrato (Figura 1c,d). Contudo, ao contrário do primeiro estádio de crescimento (26 DAT), nessa época, os tratamentos com maiores proporções de amônio favoreceram a produção de matéria seca do arroz. De acordo com França (1995), na fase de máximo perfilhamento do arroz (41 DAT), em geral, há considerável aumento na taxa fotossintética da cultura, o que lhe proporcionaria maior disponibilidade de esqueletos de carbono produzidos, nos quais o amônio seria incorporado, evitando assim acumulação excessiva desse íon na planta (Mengel \& Kirkby, 1987).

O número de panículas por planta e a produção de grãos também foram significativamente alterados pelas proporções de nitrato na solução nutritiva (Figura 2). O maior número de panículas por planta (Figura 2a,b) foi verificado, em ambas as cultivares, quando a proporção das formas de $\mathrm{N}$ foi de $75 \%$ como nitrato e 25 \% como amônio. Esses valores são superiores aos obtidos para a produção de matéria seca (Figura 1). A máxima produção de grãos foi observada quando a proporção foi de 78 e $77 \%$ para as cultivares BRS Colosso e BRSMG Conai, respectivamente (Figura 2c,d).

\section{Nutrição nitrogenada}

A atividade da redutase do nitrato (ARN) nas folhas e nas raízes do arroz, bem como os totais acumulados das formas de $\mathrm{N}$ nos tecidos vegetais, foram influenciados significativamente pelas relações $\mathrm{N}$-nitrato: $\mathrm{N}$-amônio na solução nutritiva,
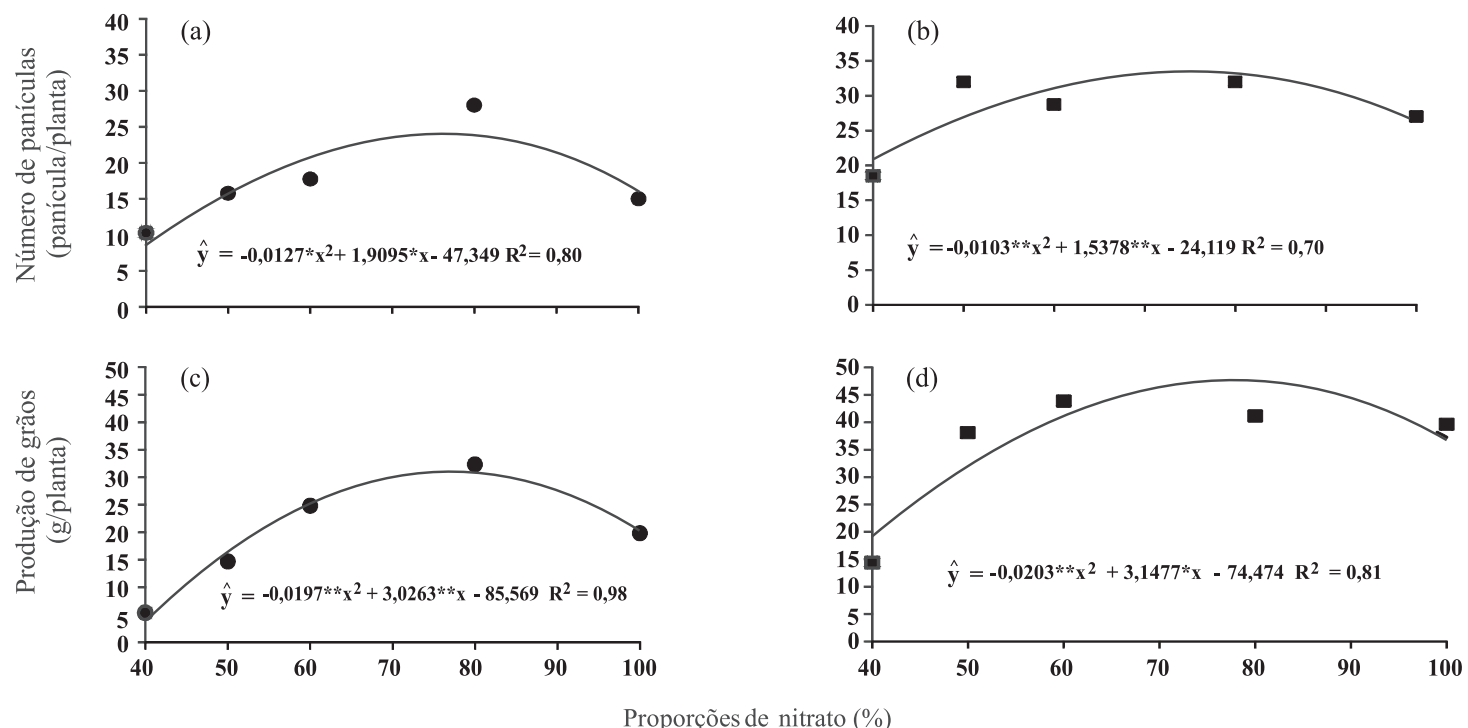

Figura 2. Número de panículas por planta e produção de grãos das cultivares de arroz BRS Colosso (a,c) e BRSMG Conai $(b, d)$ em função das proporções de nitrato na solução nutritiva. * e ** Significativo em níveis de $p<0,05$ e $p<0,01$, respectivamente. 
pelos estádios de crescimento e pela interação entre esses fatores. A ARN nas folhas, de maneira geral, foi cerca de 10 vezes maior do que nas raízes (Figura 3), confirmando que no arroz a folha é o principal órgão de redução assimilatória de $\mathrm{N}_{-} \mathrm{NO}_{3}{ }^{-}$ como ocorre com a maioria das plantas (Druart et al., 2000; Taiz \& Zeiger, 2004).

A menor ARN nas folhas de plantas de arroz de ambas as cultivares ocorreu aos 26 DAT em todas as relações N-nitrato:N-amônio. Aos 41 e 70 DAT, na cultivar BRS Colosso e aos 41 DAT, na cultivar BRSMG Conai, houve significativo aumento da atividade dessa enzima. A redução da ARN aos 70 DAT na BRSMG Conai, provavelmente, deve-se ao fato de essa cultivar apresentar ciclo mais curto (maturação aos 120 DAT), iniciando o processo de senescência fisiológica mais cedo, o que diminui a atividade da enzima mais precocemente, como relatado por Storey \& Beevers (1978). Em cultivo em solução nutritiva, Dutta \& Badruddin (1998) também observaram baixa ARN nas folhas das plantas de diversos genótipos de arroz aos 24 dias de cultivo; aos 35 dias, a atividade da enzima atingiu seu máximo, aumentando cerca de seis vezes o valor da inicial e decaindo cerca de três vezes ao valor inicial após 40 dias de cultivo.

As relações N-nitrato: $\mathrm{N}$-amônio não apresentaram efeito bem definido sobre a ARN em ambas as cultivares. Em princípio, esperava-se maior atividade da enzima nas relações com maior participação do nitrato, visto que a redutase do nitrato é de síntese induzida pelo substrato $\left(\mathrm{N}^{-} \mathrm{NO}_{3}{ }^{-}\right)$(Ali et al., 2007) e, também, pela própria necessidade da redução do $\mathrm{N}-\mathrm{NO}_{3}{ }^{-}$para $\mathrm{N}-\mathrm{NH}_{4}{ }^{+}$, a fim de que o nutriente seja assimilado. Ouko (2003) observou que em plantas de arroz cultivadas em solução
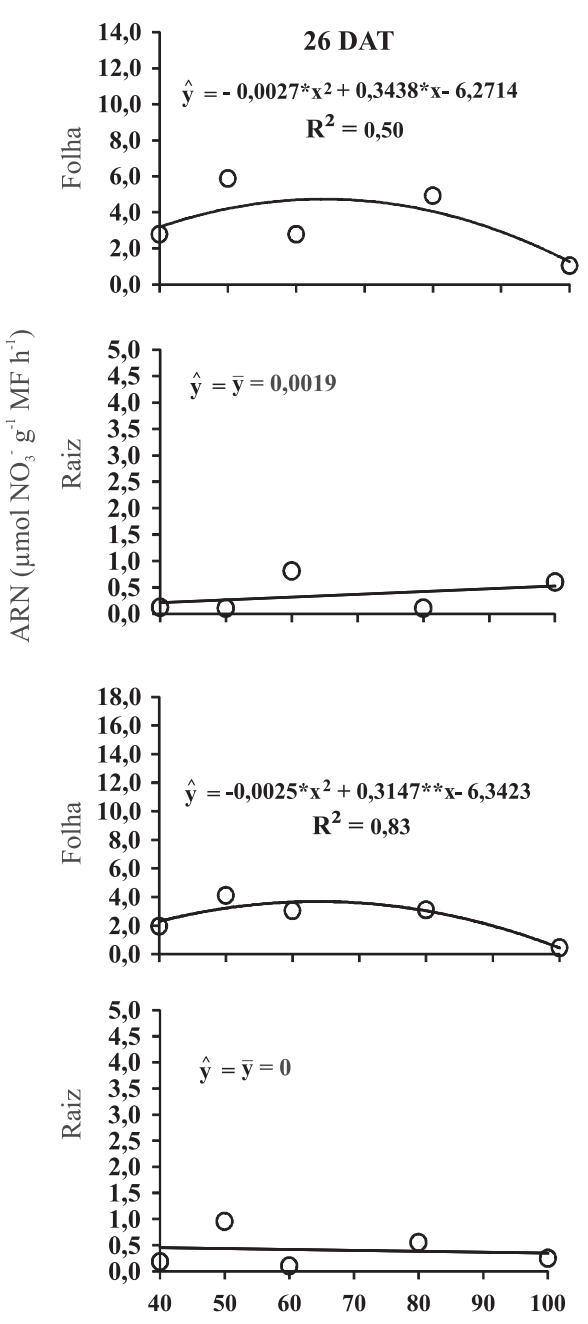
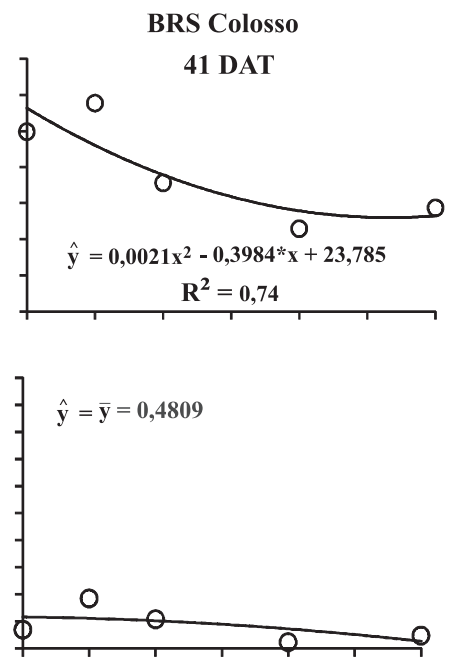

BRSMG Conai
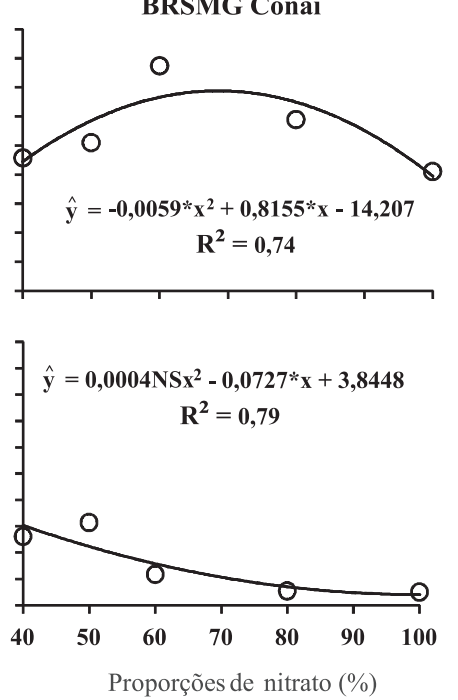
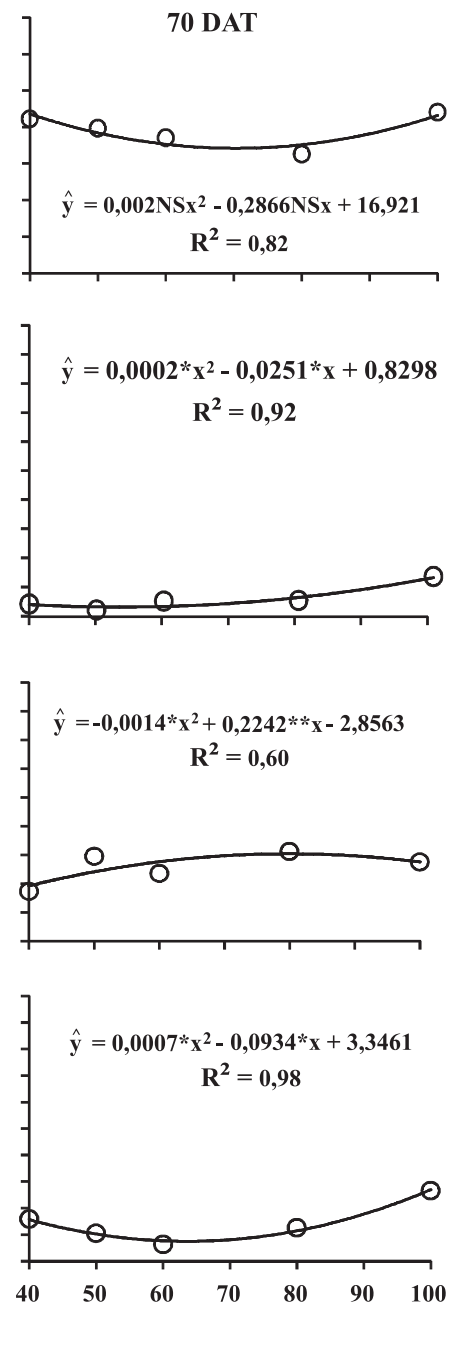

Figura 3. Atividade da redutase do nitrato nas folhas e raízes das cultivares BRS Colosso e BRSMG Conai em função das relações nitrato:amônio e dos estádios de crescimento. DAT: dias após o transplantio. **, * e NS: significativo em níveis de $p<0,05$ e $p<0,01$, respectivamente. 
nutritiva a ARN foi significativamente maior na presença de nitrato. Contudo, concentrações mais elevadas (p.ex.: $40 \mathrm{mg} \mathrm{L}^{-1}$ ) não aumentaram a atividade da enzima, indicando que ela é mais eficiente em baixas concentrações de nitrato. Tischner (2000) relata que apenas uma pequena concentração de nitrato é suficiente para induzir a síntese da redutase do nitrato. No presente trabalho, observou-se, entretanto, que no tratamento com fornecimento exclusivo de nitrato, aos 26 DAT, a ARN na folha foi bem inferior em relação aos demais tratamentos (Figura 3). Nas raízes, não se detectou tendência consistente dos estádios de crescimento ou das proporções $\mathrm{N}$-nitrato:N-amônio sobre a ARN.

Os totais acumulados de $\mathrm{N}-\mathrm{NH}_{4}{ }^{+}, \mathrm{N}-\mathrm{NO}_{3}{ }^{-}, \mathrm{N}$-total e N-orgânico, com algumas exceções, ajustaram-se ao modelo quadrático em função das proporções de nitrato em solução nutritiva (Figuras 4 e 5).

À exceção da cultivar BRSMG Conai aos 26 DAT, o acúmulo de $\mathrm{N}-\mathrm{NH}_{4}{ }^{+}$, por planta, em ambas as cultivares, mostrou tendência de decréscimo com o aumento das proporções de $\mathrm{N}^{-} \mathrm{NO}_{3}{ }^{-}$no meio de cultivo. Entretanto, aos $70 \mathrm{DAT}$, observaram-se
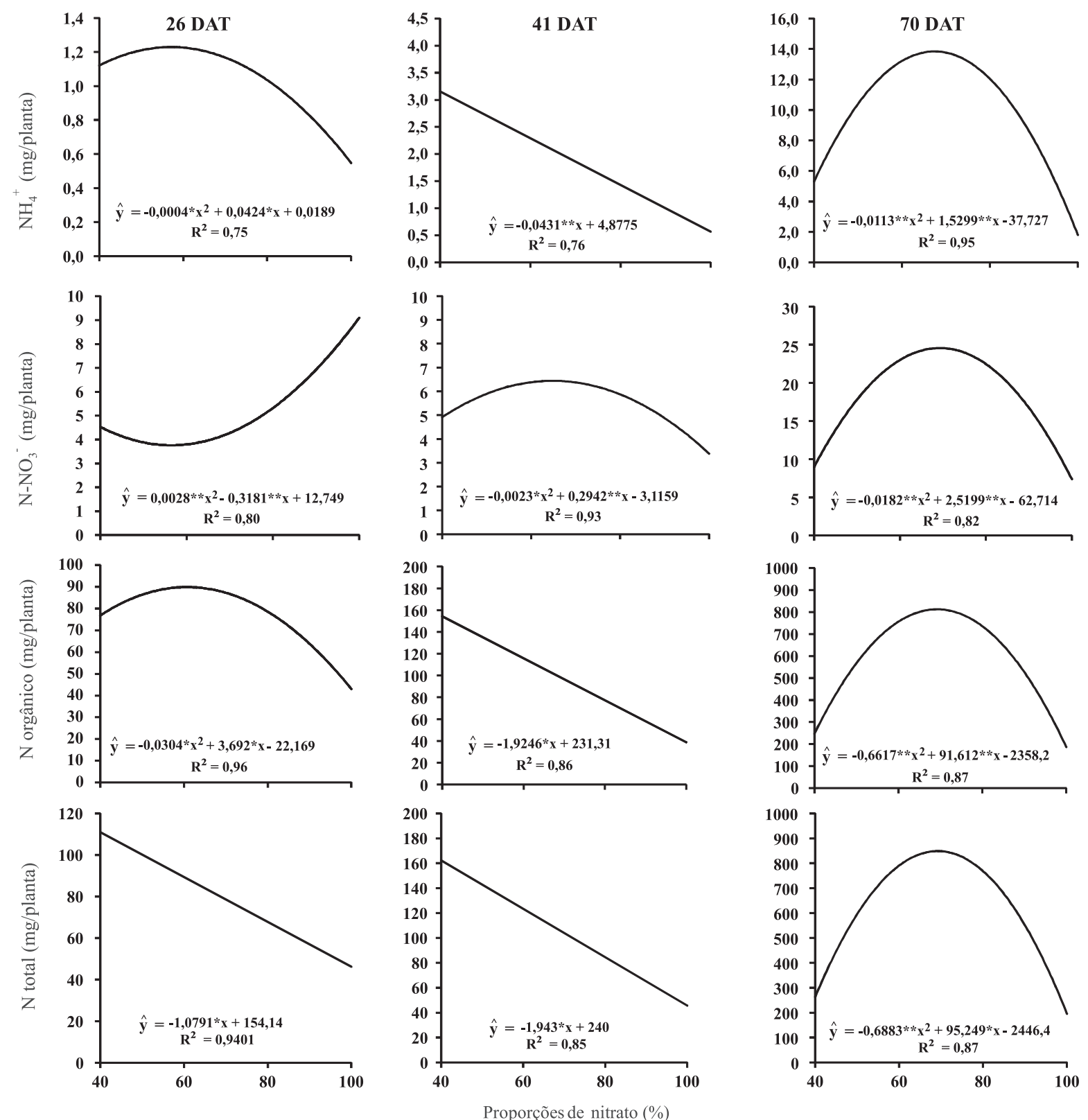

Figura 4. Totais acumulados de nitrogênio total (N-total), orgânico ( $\mathrm{N}-$-org), nítrico $\left(\mathrm{N}^{-\mathrm{NO}_{3}}{ }^{-}\right)$e amoniacal $\left(\mathrm{N}-\mathrm{NH}_{4}{ }^{+}\right)$na matéria seca da cultivar BRS Colosso em função das proporções de nitrato e dos estádios de crescimento. DAT: dias após o transplantio. **,* e NS: significativo em níveis de p $<0,05$ e p $<0,01$ e não significativo, respectivamente. 
máximos conteúdos de $\mathrm{N}-\mathrm{NH}_{4}{ }^{+}$para as proporções de nitrato de 68 e $66 \%$ para as cultivares BRS Colosso e BRSMG Conai, respectivamente, seguindo o comportamento da produção de matéria seca nesse estádio de crescimento (Figura 2). Em geral, a BRSMG Conai apresentou os maiores acúmulos de $\mathrm{N}-\mathrm{NH}_{4}{ }^{+}$mesmo produzindo menos matéria seca, o que indica possivelmente maior capacidade ou preferência dessa cultivar para absorver $\mathrm{N}-\mathrm{NH}_{4}{ }^{+}$.
Inversamente ao acúmulo de $\mathrm{N}-\mathrm{NH}_{4}{ }^{+}$, em ambas as cultivares, o acúmulo de $\mathrm{N}^{-} \mathrm{NO}_{3}{ }^{-}$, em geral, mostrou tendência de aumento com o incremento das proporções de $\mathrm{N}-\mathrm{NO}_{3}{ }^{-}$(Figuras 4 e 5). Entretanto, aos 41 e 70 DAT para a BRS Colosso, valores máximos foram observados quando as proporções de $\mathrm{N}^{-\mathrm{NO}_{3}}{ }_{3}$ fornecidas foram de 63 e $68 \%$, respectivamente, à semelhança do que ocorreu para o acúmulo de amônio para essa cultivar. $\mathrm{O}$ aumento
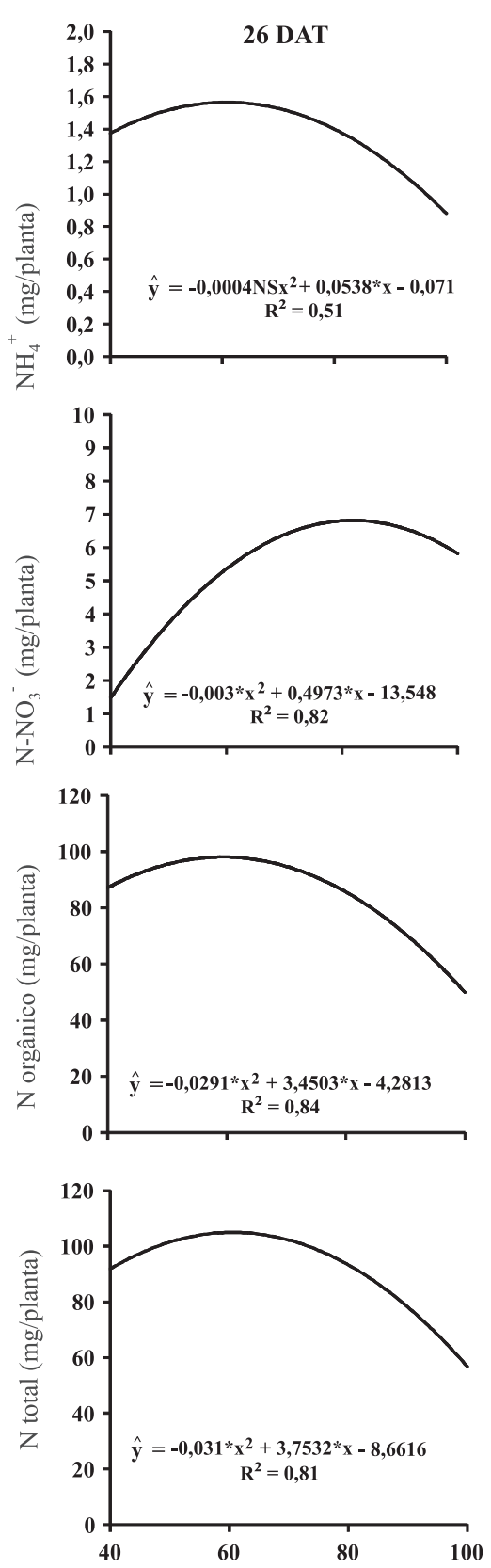
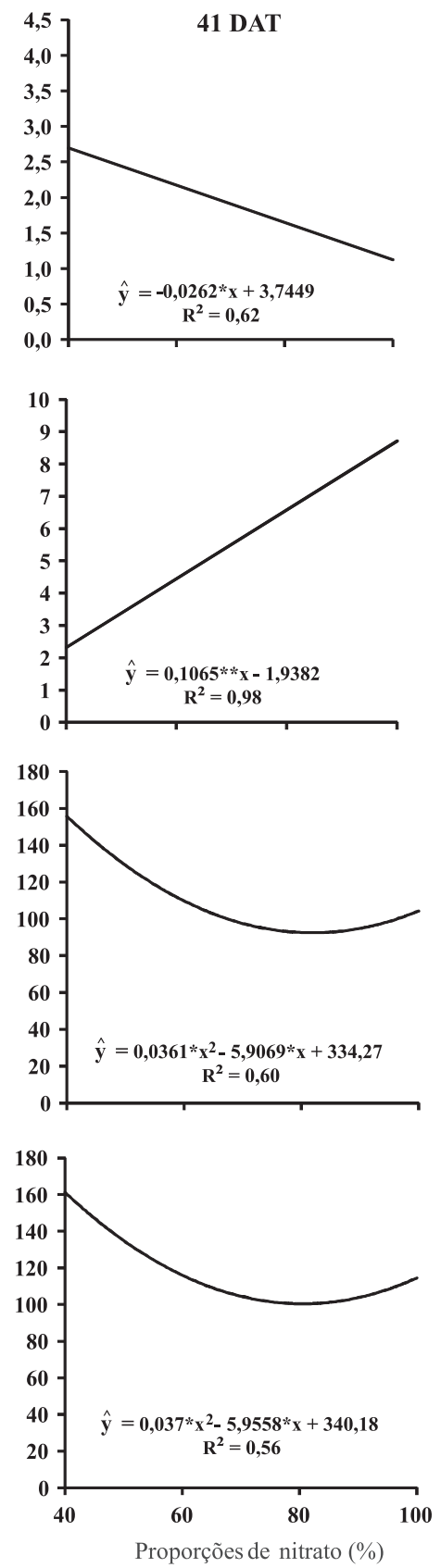
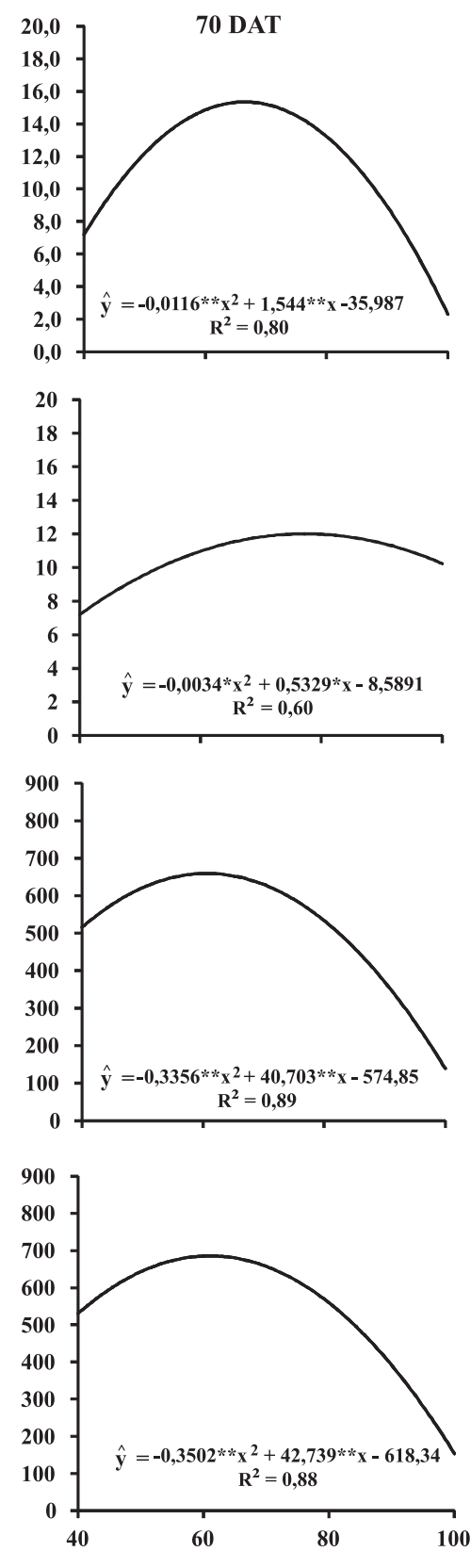

Figura 5. Totais acumulados de nitrogênio total (N-total), orgânico (N-org), nítrico $\left(\mathrm{N}^{-\mathrm{NO}_{3}}{ }^{-}\right)$e amoniacal $\left(\mathrm{N}-\mathrm{NH}_{4}{ }^{+}\right)$na matéria seca da cultivar BRSMG Conai em função das proporções de nitrato e dos estádios de crescimento. ${ }^{1} \mathrm{DAT}$ : dias após o transplantio. $* *, *$ e NS: significativo em níveis de p $<0,05$ e p $<0,01$ e não significativo, respectivamente. 


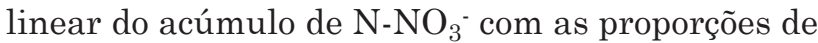
nitrato no meio de cultivo para a cultivar BRSMG Conai, aos 41 DAT, pode estar relacionado a uma maior concentração da enzima redutase do nitrato agindo como transportadora desse ânion (Tischner, 2000; Taiz \& Zeiger, 2004), tendo em vista o aumento significativo de sua atividade na redução de nitrato nesse período de avaliação, sobretudo para a cultivar BRSMG Conai (Figura 3). Aos 26 DAT, contudo, a tendência de aumento do acúmulo na planta de nitrato com o aumento das proporções deste ânion em solução para ambas as cultivares não poderia ser explicada por esse mecanismo, tendo em vista a baixa ARN nesse período de avaliação. Nesse caso, aparentemente o nitrato acumulado deve-se a uma absorção passiva, principalmente em se tratando de plantas ainda em estádio inicial de crescimento, onde a concentração intercelular de $\mathrm{N}-\mathrm{NO}_{3}{ }^{-}$ainda é baixa em relação ao meio externo, o que favorece sua absorção por difusão (King et al., 1992).

Os acúmulos de $\mathrm{N}$ orgânico, em ambas as cultivares, assim como para o amônio, apresentam tendência de decréscimo com o aumento das proporções de $\mathrm{N}^{-\mathrm{NO}_{3}}{ }^{-}$em solução nutritiva aos 26 e 41 DAT (Figuras 4 e 5). Aos 70 DAT, houve picos no acúmulo dessa fração de $\mathrm{N}$, condicionados pelas proporções de $\mathrm{N}-\mathrm{NO}_{3}{ }^{-}$de 69 e $61 \%$ para a BRS Colosso e BRSMG Conai, respectivamente. O N total acumulado por planta também decresceu com o aumento das proporções de $\mathrm{N}^{-\mathrm{NO}_{3}}{ }^{-}$no meio de cultivo, diminuindo linearmente seus valores aos 26 e 41 DAT, para a cultivar BRS Colosso, e de forma quadrática nos demais casos (Figuras 4 e 5).

Em uma análise global das frações de $\mathrm{N}$, é possível verificar que os totais de $\mathrm{N}-\mathrm{NO}_{3}{ }^{-}$acumulados por planta aos $26 \mathrm{DAT}$, em ambas as cultivares, em geral, são semelhantes ou superiores aos observados aos 41 DAT. Considerando que a matéria seca produzida nesse estádio foi significativamente superior àquela produzida aos $26 \mathrm{DAT}$ (Figura 1), pode-se propor que na fase inicial de crescimento (26 DAT), principalmente nas maiores proporções de $\mathrm{N}-\mathrm{NO}_{3}$ no meio, grande parte do nitrato acumulado pelas plantas não foi assimilada em compostos orgânicos. Esse comportamento seria devido à baixa $\mathrm{ARN}$ observada aos 26 DAT (Figura 3) nas folhas, em ambas as cultivares. Cabe ressaltar que a diminuição drástica da acumulação das formas de $\mathrm{N}$ aos $70 \mathrm{DAT}$ pelo fornecimento exclusivo de $\mathrm{N}-\mathrm{NO}_{3}-$ mostra que, mesmo havendo aumento significativo da ARN aos $41 \mathrm{DAT}$, os prejuízos iniciais pelo excesso de nitrato foram irreversíveis, alterando inclusive a produção de grãos (Figura 2). Esses resultados reforçam a hipótese de que a baixa capacidade de aproveitamento do nitrato pelo arroz na fase inicial de crescimento pode estar associada ao pior desempenho da cultura no sistema de plantio direto.
$\mathrm{O}$ amônio em maiores proporções que o nitrato também proporcionou decréscimos na produção de matéria seca no início do perfilhamento e na época de emissão de panículas (Figura 1), bem como na produção de grãos (Figura 2). O efeito depressivo do excesso de $\mathrm{N}-\mathrm{NH}_{4}{ }^{+}$no crescimento e produção das culturas tem sido observado em outros trabalhos (Jakobs \& Gupen, 1997; Jacob Neto et al., 1998; Holzschuh et al., 2009). A toxidez observada não se deve propriamente ao acúmulo de amônio $\left(\mathrm{NH}_{4}{ }^{+}\right)$, e sim à amônia $\left(\mathrm{NH}_{3}\right)$ formada (Mengel \& Kirkby, 1987). Quando em maiores concentrações no meio, este íon acumula-se no citoplasma celular, na matriz mitocondrial ou no estroma do cloroplasto, trazendo diversas consequências negativas para o metabolismo vegetal (Britto \& Kronzucker, 2002). Outro efeito que deve ser considerado é a interação iônica (inibição competitiva) no meio de cultivo do amônio com outros cátions, como o $\mathrm{Ca}^{+2}$ e $\mathrm{K}^{+}$ (Marschner, 1995; Holzschuh et al., 2009).

\section{CONCLUSÕES}

1. A máxima produção de matéria seca da parte aérea das cultivares de arroz ocorreu para proporções de nitrato entre 58 e $68 \%$, em relação ao amônio. Quanto ao número de panículas por planta e à produção de grãos, esses valores estiveram entre 75 e $78 \%$.

2. A causa do menor crescimento e da produção das cultivares de arroz quando se forneceu apenas nitrato foi o acúmulo excessivo dessa forma nos tecidos das plantas na fase inicial do seu crescimento, devido à baixa atividade da redutase do nitrato nessa fase. Entretanto, houve efeito prejudicial também pelo excesso de amônio, quando este se encontrava em maiores proporções que o nitrato na solução nutritiva.

\section{LITERATURA CITADA}

ALI, A., SIVAKAMI, S. \& RAGHURAM, N. Effect of nitrate, nitrite, glutamate, glutamine and 2-oxoglutarate on RNA, levels and enzyme activities of nitrate reductase and nitrite reductase in rice. Physiol. Molec. Biol. Plants, 13:17-25, 2007.

ARAUJO, J.L. Atividade da redutase do nitrato, crescimento e produção de grãos do arroz. Lavras, Universidade Federal de Lavras, 2005. 61p. (Tese de Mestrado)

BRITTO, D.T. \& KRONZUCKER, H.J. $\mathrm{NH}_{4}{ }^{+}$toxicity in higher plants: A critical review. J. Plant Physiol., 159:567-584, 2002.

CRAMER, M.D. \& LEWIS, A.M. The influence of nitrate and ammonium nutrition on the growth of wheat (Tricum aestivum) and maize (Zea mays) plants. Ann. Bot., 72:359365, 1993. 
DELÚ FILHO, N.; OLIVEIRA, L.E.M. \& ALVES, J.D. Atividade da redutase do nitrato em plantas jovens de seringueira (Hevea brasiliensis Muell. Arg.): Otimização das condições de ensaio e ritmo circadiano. R. Árvore, 21:329-336, 1997.

DUAN, Y.H.; ZHANG, Y.L.; YE, L.T.; FAN, X.R.; XU, G.H. \& SHEN, Q.R. Responses of rice cultivars with different nitrogen use efficiency to partial nitrate nutrition. Ann. Bot., 99:1153-1160, 2007.

DUAN, Y.H.; ZHANG, Y.L.; SHEN, Q.R. \& WANG, S.W. Nitrate effect on rice growth and nitrogen absorption and assimilation at different growth stages. Pedosphere, 16:7707-7017, 2006.

DUTTA, R.K. \& BADRUDDIN, M. Fertillizer-N scheduling based ontogenetic characteristics of nitrate reductase in rice genotypes. Intern. Rice Comm. Newsletter, 49:1-7, 1998.

DRUART, N.; GOUPIL, P.; DEWAELE, E.; BOUTIN, J.P. \& RAMBOUR, S. Nitrate assimilation in chicory roots (Cichorium intybus L.) which acquire radial growth. J. Exper. Bot., 51:539-546, 2000.

EPSTEIN, E. \& BLOOM, A. Nutrição mineral de plantas: Princípios e perspectivas. Londrina, Editora Planta, 2006. 169p.

FAGERIA, N.K.; SANTOS, A.B. \& STONE, L.F. Manejo de nitrogênio em arroz irrigado. Santo Antônio de Goiás, Embrapa, 2003. (Circular Técnica, 58)

FARINELLI, R.; PENARIOL, F.G.; FORNASIERI FILHO, D. \& BORDIN, L. Características agronômicas de arroz de terras altas sob plantio direto e adubação nitrogenada e potássica. R. Bras. Ci. Solo, 28:447-454, 2004.

FRANÇA, M.G.C. Análise do crescimento e do acúmulo de nitrogênio em duas cultivares de arroz contrastantes em hábito de crescimento. Seropédica, Universidade Federal Rural do Rio de Janeiro, 1995.135p. (Tese de Mestrado)

GANMORE-NEUMANN, R. \& KAFKAFI, U. Root temperature and percentage $\mathrm{NO}_{3}{ }^{-} / \mathrm{NH}_{4}{ }^{+}$effect on tomato development: ii. nutrients composition of tomato plants. Agron. J., 72:762$766,1980$.

HOAGLAND, D.R. \& ARNON, D.I. The water-culture method for growing plants without soil. Berkeley, California Agricultural Experiment Station, 1950. p.347.

HOLZSCHUH, M.J.; BOHNEN, H.; ANGHINONI, I.; MEURER, E.J.; CARMONA, F.C. \& COSTA, S.E.V.G.A. Resposta do arroz irrigado ao suprimento de amônio e nitrato. R. Bras. Ci. Solo, 33:1323-1331, 2009.

JACOB NETO, J.; GOI, R.S. \& SPRENT, J.I. Efeito de diferentes formas de nitrogênio na nodulação e crescimento de Acacia mangeum. Flor. Amb., 51:104-110, 1998.

JAKOBS, B.M. \& GÜLPEN, M. Influences of the different nitrate to ammonium ratios on chlorosis, cation concentrations and biding forms of $\mathrm{Mg}$ and $\mathrm{Ca}$ in needles of $\mathrm{Mg}$-deficient Norway spruce. Plant Soil, 188:267-277, 1997.
KING, B.J.; SIDDIQI, M.Y. \& GLASS, A.D.M. Studies of the uptake of nitrate in barley. V. estimation of root cytoplasmic nitrate concentration using nitrate reductase activityimplications for nitrate influx. Plant Physiol., 99:15821589, 1992.

MALAVOLTA, E. Elementos de nutrição mineral de plantas. São Paulo, Agronômica Ceres, 1980. 251p.

MALAVOLTA, E.; VITTI, G.C. \& OLIVEIRA, S.A. Avaliação do estado nutricional das plantas: Princípios e aplicações. 2.ed. Piracicaba, Associação Brasileira da Potassa e do Fosfato, 1997. 319p.

MARSCHNER, H. Mineral nutrition of higher plants. San Diego, Academic Press, 1995. 889p.

MATSUO, T. \& HOSHIKAWA, K. Science of the rice plant: Morphology. Tokio, Food and Agriculture Policy Research Center, 1993. 700p.

MENGEL, K. \& KIRKBY, E.A. Principles of plant nutrition. Bern, International Potash Institute, 1987. 687p.

NAMBIAR, P.T.C.; REGO, T.J. \& SRINIVASA RAO, B. Nitrate concentration and nitrate reductase activity in the leaves of three legumes and three cereals. Ann. Appl. Biol., 112:547$553,1988$.

NOMA, T. \& HIROSE, D. Effects of ammonium and nitrate on the development of the rice root system. Japan J. Crop Sci., 74:270-275, 2005.

OAKS, A. Primary nitrogen assimilation in higher plants and its regulation. Can. J. Bot., 72:739-750, 1994.

OUKO, M.O. Nitrate reductase activity in rice as a screening tool for weed competitiveness. Bonn, Faculty of Agriculture, University of Bonn, 2003. 85p. (Tese de Doutorado)

QIAN, X.; SHEN, Q.; XU, G.; WANG, J. \& ZHOU, M. Nitrogen forms effects on yield and nitrogen uptake of rice crop grown in aerobic soil. J. Plant Nutr., 27:1061-1076, 2004.

SOARES, A.A. Desvendando o segredo do insucesso do plantio direto do arroz de terras altas. Inf. Agropec., 25:58-66, 2004.

STOREY, R. \& BEEVERS, L. Enzimology of glutamine metabolism related a senescence and seed development in the pea (Pisum sativum L.). Plant Physiol., 61:494-500, 1978.

TAIZ, L. \& ZEIGER, E. Fisiologia vegetal. Porto Alegre, Artmed, 2004. 719p.

TISCHNER, R. Nitrate uptake and reduction in higher and lower plants. Plant, Cell Environ., 23:1005-1024, 2000.

TEDESCO, M.J., GIANELLO, C.; BISSANI, C.A.; BOHNEN, H. \& VOLKWEISS, S.J. Análises de solo, plantas e outros materiais. 2.ed. Porto Alegre, UFRGS, Departamento de Solos, 1985, 174p. (Boletim Técnico n. 5)

WADA, G.; SHOGI, S. \& MAE, T. Relationship between nitrogen absorption on growth and yield of rice plant. Japan Agric. Res. Quart., 20:135-144, 1986. 